\title{
Human Plasma Transport of Vitamin D after Its Endogenous Synthesis
}

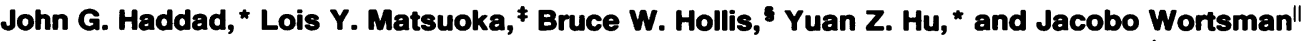 \\ * Department of Medicine, University of Pennsylvania, Philadelphia, Pennsylvania 19104; ${ }^{\ddagger}$ Department of Dermatology, \\ Jefferson Medical College, Philadelphia, Pennsylvania 19107; \$ Department of Pediatrics, Medical College of South Carolina, \\ Charleston, South Carolina 29425; and "Department of Medicine, Southern Illinois University, Springfield, Illinois 62794
}

\begin{abstract}
Transport of vitamin $D_{3}$ from its sites of cutaneous synthesis into the circulation has been assumed to be via the plasma vitamin $D$ binding protein (DBP). We studied vitamin $D$ transport from the skin in seven healthy volunteers who received whole body irradiation with $27 \mathrm{~mJ} / \mathrm{cm}^{2}$ dosage of ultraviolet $B$ light (290-320 nm). Samples of venous blood were collected serially in EDTA and immediately chilled. In $\mathrm{KBr}$, plasma samples were ultracentrifuged to provide a rapid separation of proteins of density $<$ and $>1.3 \mathrm{~g} / \mathrm{ml}$. Upper and lower phases and serial fractions were analyzed for vitamin $D_{\mathbf{3}}$ (extraction, HPLC), cholesterol (enzyme assay), and human DBP (hDBP) (radial immunodiffusion). Total plasma vitamin D (basal level $<1 \mathrm{ng} / \mathrm{ml}$ ) increased by $10 \mathrm{~h}$ and peaked at $24 \mathrm{~h}$ $(9 \pm 1 \mathrm{ng} / \mathrm{ml}) .98 \%$ of the $D_{3}$ remained at the density $>1.3$ layers for up to $7 \mathrm{~d}$, whereas cholesterol $(>85 \%)$ was detected at density $<1.3$ and all of the $\mathrm{hDBP}$ was at density $>1.3$. In three volunteers who each ingested $1.25 \mathrm{mg}$ of vitamin $D_{2}$, the total plasma $D_{2}$ increased to $90 \pm 32 \mathrm{ng} / \mathrm{ml}$ by $4 \mathrm{~h}$, and the $D_{2}$ was evenly distributed between the upper and lower layers at 4 , 8 , and $24 \mathrm{~h}$ after the dose, indicating a continuing association of the vitamin with chylomicrons and lipoproteins, as well as with hDBP. Actin affinity chromatography removed $D_{3}$ from plasma of irradiated subjects, indicating the association of the $D_{3}$ with DBP. These findings indicate that endogenously synthesized vitamin $D_{3}$ travels in plasma almost exclusively on DBP, providing for a slower hepatic delivery of the vitamin $D$ and the more sustained increase in plasma 25-hydroxycholecalciferol observed after depot, parenteral administration of vitamin D. In contrast, the association of orally administered vitamin $D$ with chylomicrons and lipoproteins allows for receptor-mediated, rapid hepatic delivery of vitamin $D$, and the reported rapid but less-sustained increases in plasma 25-hydroxycalciferol. ( $J$. Clin. Invest. 1993. 91:2552-2555.) Key words: vitamin D • transport • skin • plasma proteins
\end{abstract}

Portions of this work were presented at the 14th Annual Meeting of the American Society for Bone and Mineral Research, Minneapolis, MN, 1 October 1992 (J. Bone Miner. Res. 7[Suppl. 1]:S158).

Address reprint requests to Dr. John G. Haddad, Department of Medicine, University of Pennsylvania, School of Medicine, 422 Curie Blvd., 611 CRB, Philadelphia, PA 19104-6149.

Received for publication 9 November 1992 and in revised form 21 January 1993.

J. Clin. Invest.

a. The American Society for Clinical Investigation, Inc.

$0021-9738 / 93 / 06 / 2552 / 04 \$ 2.00$

Volume 91, June 1993, 2552-2555

\section{Introduction}

Vitamin D is a precursor of a renal steroid hormone, 1,25-dihydroxyvitamin D (1). This precursor, however, cannot be provided by enzymatic synthesis. Its supply depends on ultraviolet (UV) irradiation of the skin or absorption from the diet. Since few natural foodstuffs contain much vitamin $D(2)$, observers consider the endogenous, cutaneous production of cholecalciferol to be the physiological mechanism of precursor supply (2-5).

Distinct differences are recognized for the cutaneous synthesis vs. diet-derived supply of vitamin $\mathrm{D}(2,6)$. A more efficient and sustained supply of vitamin D is associated with UV irradiation of the skin or parenteral administration of vitamin D $(2,6)$. In contrast, oral vitamin D consumption leads to rapid but less sustained availability of sterol and a similar pattern of increase in the hepatic metabolite, 25-hydroxycholecalciferol (2, 6-9).

Many studies have addressed the mode of vitamin D transport after oral consumption (6), but no direct studies of the plasma transport of cutaneously-derived vitamin D are reported. It has been assumed that vitamin D synthesized in skin enters the blood stream on the plasma binding protein for vitamin D and its metabolites (DBP) ${ }^{1}$ and this assumption is based on in vitro studies of the relative potency of vitamin $D$ in binding to DBP as compared with 7-dehydroxycholesterol, lumisterol, tachysterols ${ }_{3}$ and pre- $\mathrm{D}_{3}(10-12)$. However, other plasma carriers are recognized and some facilitate hepatic (1315 ) and hepatocyte (16) entry of vitamin $D$, presumably via their receptors on hepatocyte plasma membranes. Our study addresses the nature of plasma vitamin D transport after UV irradiation of human volunteers.

\section{Methods}

Materials. $\mathrm{KBr}$ was purchased from Aldrich Chemical Co. (Milwaukee, WI). Affigel-15 resin was bought from Bio-Rad Laboratories (Richmond, CA). Crystalline vitamins $\mathrm{D}_{3}$ and $\mathrm{D}_{2}$ and a cholesterol enzyme assay kit for cholesterol were purchased from Sigma Chemical Co. (St. Louis, MO).

Volunteers. The volunteer population was composed of 10 healthy subjects ( 3 women, 7 men, ages 22-54 y) who had no history of skin, hepatic, or renal disease. None were taking vitamin $D$, anticonvulsants, or glucocorticosteroids, and all subjects gave their informed consent to the institutional review boards at the University of Pennsylvania School of Medicine or the Jefferson Medical College.

Cutaneous irradiation. Seven subjects were exposed to $27 \mathrm{~mJ} / \mathrm{cm}^{2}$ of UV-B light (290-320 mm). Venous blood samples were taken at baseline, 10, 24, 72, and $168 \mathrm{~h}$ after the UV-B exposure, immediately

1. Abbreviation used in this paper: DBP, vitamin D binding protein. 
transferred to tubes containing $0.2 \%$ (wt/vol) EDTA, and placed on ice. Irradiation experiments were done in January 1992.

Oral dosage. Three fasting subjects each swallowed a commercial $50,000 \mathrm{IU}(1.25 \mathrm{mg})$ capsule of ergocalciferol, followed by $240 \mathrm{ml}$ of distilled water. Venous blood samples were obtained at baseline, 4, 8, $48 \mathrm{~h}$ after the oral dose. Blood was immediately transferred to tubes containing EDTA and placed on ice.

Sample preparation. Blood from volunteers was centrifuged within $1 \mathrm{~h}$ of collection in a refrigerated centrifuge. Plasma aliquots for total plasma vitamin $\mathrm{D}$ analysis were stored at $-20^{\circ} \mathrm{C}$. To carry out a rapid separation of plasma proteins of density less than and greater than 1.3 $\mathrm{g} / \mathrm{ml}$, the method of Chung et al. was used (17). In brief, unfrozen plasma aliquots $(1.5 \mathrm{ml})$ were dispensed into tubes containing preweighed $\mathrm{KBr}(513 \mathrm{mg})$. After mixing, plasma was added to $3.5 \mathrm{ml}$ of $0.15 \mathrm{M} \mathrm{NaCl}$ in ultracentrifuge tubes before heat sealing. Tubes were centrifuged at $10^{\circ} \mathrm{C}$ in a $\mathrm{Ti} 65.2$ vertical rotor at $65,000 \mathrm{rpm}$ in an ultracentrifuge (model L8M; Beckman Instruments, Inc., Fullerton, CA) for $\mathbf{4 5} \mathrm{min}$. Fractions were collected via bottom punctures, permitting the isolation of the lower ( $30 \%$ of volume, density $>1.3 \mathrm{~g} / \mathrm{ml}$ ) and upper ( $70 \%$ of volume, density $<1.3 \mathrm{~g} / \mathrm{ml}$ ) phases.

Analyses. Quantitation of vitamins $\mathrm{D}_{3}$ and $\mathrm{D}_{2}$ was carried out as previously reported (18). In brief, organic solvent extracts were applied to HPLC columns and the vitamin D fractions were quantitated by UV absorption spectrometry at $264 \mathrm{~nm}$.

Cholesterol oxidase reagents were used to quantitate total cholesterol in ultracentrifuge fractions by visible spectrometry (Sigma kit).

DBP was quantitated in a radial immunodiffusion assay as reported earlier (19).

\section{Results}

In pilot experiments to assess the validity and reproducibility of the plasma density separations in our laboratory, we analyzed total plasma content, as well as density less than and greater than $1.3 \mathrm{~g} / \mathrm{ml}$ for DBP and cholesterol. For 16 separate human plasma samples, most of the DBP $(89+2.1 \%$, SEM $)$ and cholesterol $(94+2.3 \%, \mathrm{SEM})$ in plasma was recovered in the density gradient fractions. Table I displays the upper and lower phase distribution of the substances after centrifugation. Fig. 1 depicts the distribution of DBP and cholesterol in continuous ultracentrifuge fractions of fasting human plasma. The DBP is contained in the lower third of the gradient, whereas the cholesterol profile reflects its association with several carriers, including some binding to high-density lipoproteins and density $>1.3 \mathrm{~g} / \mathrm{ml}$ molecules $(18)$.

At baseline, total plasma cholecalciferol levels were $<2$ $\mathrm{mg} / \mathrm{ml}$ or undetectable (Fig. $2 A$ ). After irradiation, the total

Table I. Distribution of Cholesterol and hDBP in Ultracentrifuged Plasma

\begin{tabular}{lcc}
\hline Experiment & Density $<1.30$ & Density $>1.30$ \\
\hline No. 1 & & \\
Cholesterol & $87.6 \pm 0.6 \%$ & $12.5 \pm 0.6 \%$ \\
hDBP & $<5 \%$ & $>95 \%$ \\
No. 2 & & \\
Cholesterol & $85.3 \% \pm 1.2 \%$ & $14.7 \% \pm 1.2 \%$ \\
hDBP & $<5 \%$ & $>95 \%$ \\
\hline
\end{tabular}

Data are expressed as mean \pm SEM for eight plasma samples in each experiment.

hDBP, human plasma protein for vitamin D and its metabolites.

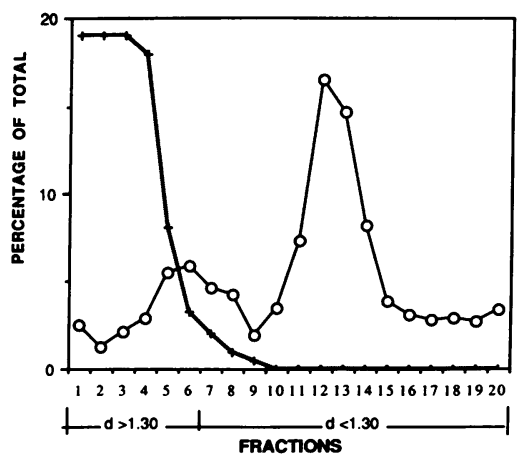

Figure 1. The distribution of plasma cholesterol $(0)$ and DBP (+) in ultracentrifuge density gradient fractions.

plasma cholecalciferol levels increased by $10 \mathrm{~h}$, peaked at $24 \mathrm{~h}$, and decreased by 3 and $7 \mathrm{~d}$.

Fig. $2 \mathrm{~B}$ depicts the distribution of cholecalciferol in plasma before and after cutaneous irradiation. As shown, almost all of the baseline and postirradiation plasma cholecalciferol was associated with the fractions of density $>1.3 \mathrm{~g} / \mathrm{ml}$ fractions.

After the oral dosage of vitamin $\mathrm{D}_{2}$, large increases in plasma vitamin $\mathrm{D}_{2}$ were observed (Fig. $3 \mathrm{~A}$ ). Baseline plasma $\mathrm{D}_{2}$ levels were undetectable in two subjects and $1 \mathrm{ng} / \mathrm{ml}$ plasma in the other subject. In contrast to the cutaneous irradiation supply of vitamin $D_{3}$, the plasma vitamin $D_{2}$ levels declined briskly toward baseline by $2 \mathrm{~d}$.

The distribution of orally administered vitamin $D_{2}$ in plasma was very different from that observed after cutaneous production of vitamin $D_{3}$. As shown in Fig. $3 B, 41 \%$ of the plasma $\mathrm{D}_{2}$ was found in the fractions of density $<1.3 \mathrm{~g} / \mathrm{ml}$ at 4 $\mathrm{h}$ after the dose. This distribution in the lower density fractions decreased slightly by 8 and $24 \mathrm{~h}$. After this large dose, it is clear that the vitamin is associated with low- and high-density carriers.

When plasma from UV light-treated subjects (24-h samples) was subjected to actin affinity chromatography to remove DBP (20), all of the vitamin D was removed from these plasmas, indicating that the vitamin $\mathrm{D}$ was bound to DBP.

\section{Discussion}

Our results indicate that high density or nonlipoprotein carriers are responsible for the blood transport of recently synthesized, endogenous vitamin $D_{3}$. Since the vitamin $D_{3}$ was removed from these plasmas by actin affinity chromatography, the cutaneously produced vitamin $\mathrm{D}_{3}$ was bound to DBP as previously assumed (10-12). Our data conform to the recognized, gradual egress of cutaneously synthesized vitamin $D_{3}(2$, $6,21,22$ ), and underscore the differences between the cutaneous and dietary sources of the vitamin (2).

Diet-derived vitamin $\mathrm{D}$ requires the components of lipid absorption, as indicated by the association of absorbed vitamin $D$ with chylomicron carriers in chyle (23). When absorbed vitamin $\mathrm{D}$ reaches the subclavian vein, some of it is presented to the liver on the chylomicron remnants via specific receptormediated uptake and some redistributes to other plasma carriers such as DBP, lipoproteins, and albumin (6, 13, 24-26). Since DBP is present in lymph and chyle, some of the absorbed vitamin D redistributes to DBP during chyle transport (26, 27). The hepatic ingress of vitamin $D$ is modulated by its plasma carriers, and experiments with liver perfusions $(14,15)$ 
A

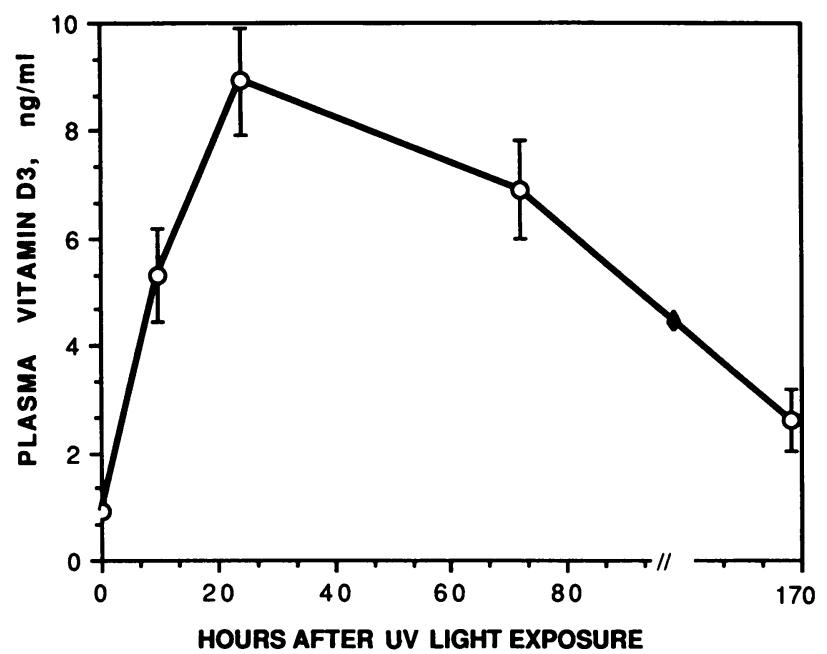

B

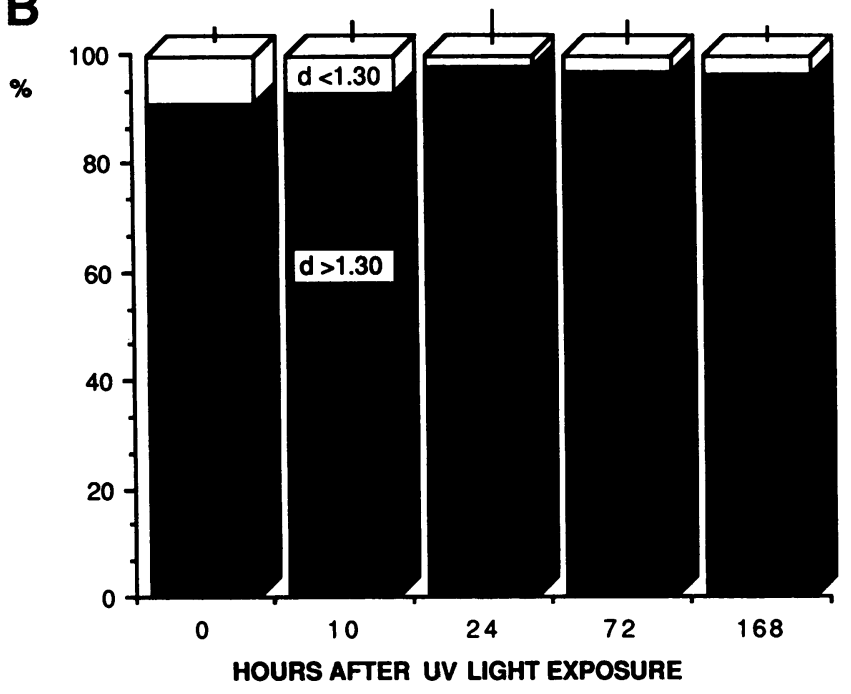

Figure 2. $(A)$ Total plasma vitamin $\mathrm{D}_{3}$ concentrations before and after whole body UV-B light irradiation of seven subjects. Mean values and SEM are shown. Vitamin $D_{2}$ was not detected $(<1 \mathrm{ng} / \mathrm{ml})$ in any of the samples. $(B)$ The distribution of vitamin $\mathrm{D}_{3}$ in density gradient fractions of plasma obtained before and after UV irradiation. Vertical bars depict the SEM.

and hepatocytes (16) indicate that carriers with liver membrane receptors (chylomicron remnants, LDL) greatly facilitate hepatic vitamin D uptake. In contrast, albumin and HDL are less facilitative, and vitamin D bound to DBP is least apt to enter the liver or hepatocytes $(15,16)$.

Many previous reports of vitamin D's disposition in vivo are difficult to reconcile, and this is probably due to the various modes of parenteral vitamin D administration, including organic solvents $(15,28)$, intralipid (13), plasma (29), and oily depot injections (9). In addition, although DBP is the only stereoselective plasma carrier of vitamin $D$, most of the other lower affinity carriers are in high concentration in plasma. When simply mixed with plasma directly, vitamin $\mathrm{D}$ does associate, to some extent, with non-DBP carriers (15). It seems likely, therefore, that administration of vitamin D intrave-
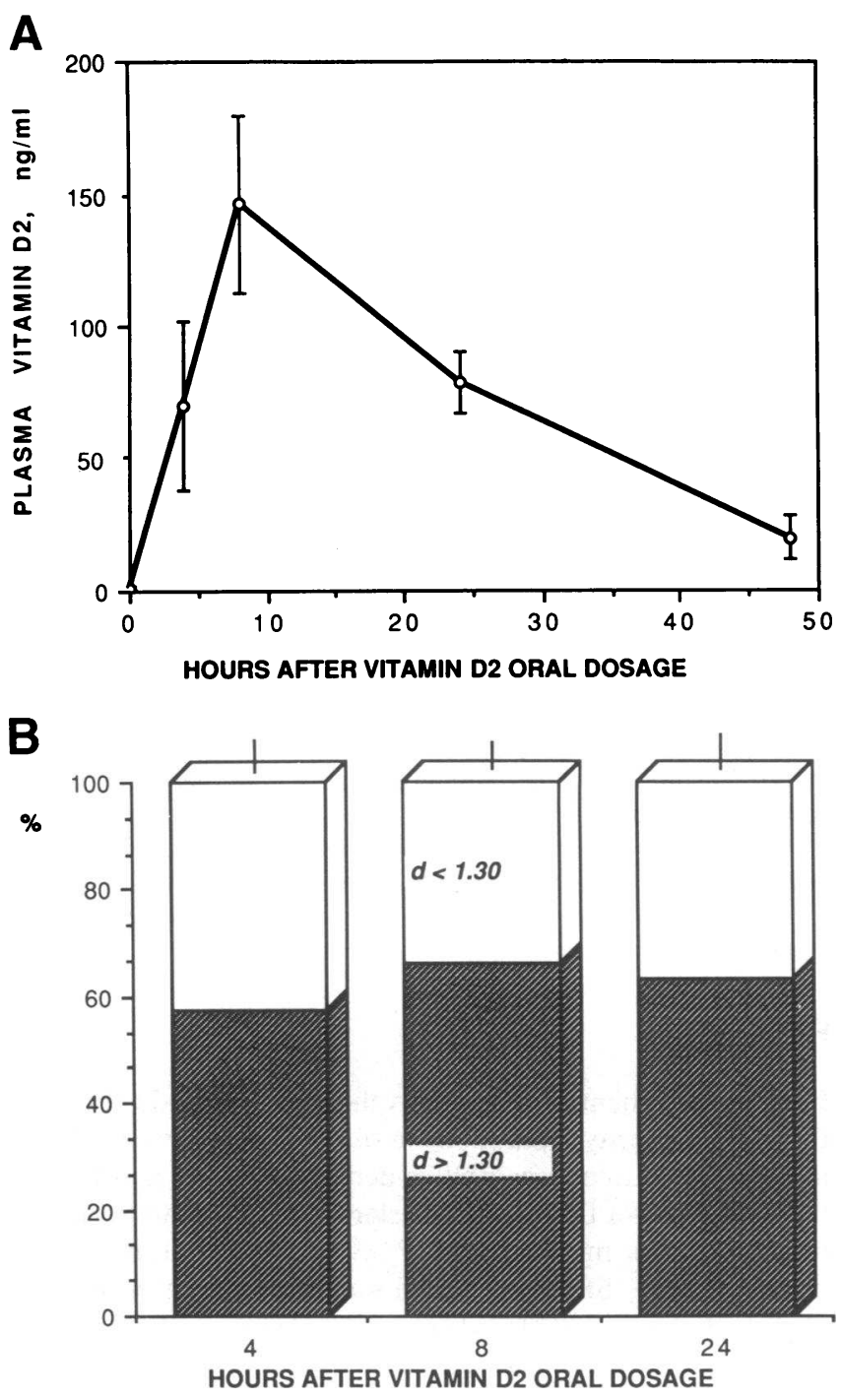

Figure 3. $(A)$ Total plasma vitamin $\mathrm{D}_{2}$ concentrations after oral dosage to three volunteers. Mean values and SEM are shown. Basal concentrations were undetectable in two of the subjects. $(B)$ The distribution of vitamin $\mathrm{D}_{2}$ in density gradient fractions of plasma obtained before and after oral dosage of vitamin $D_{2}$. Vertical bars depict the SEM.

nously in solvents (e.g., propylene glycol, ethanol) will result in the vitamin's association with non-DBP carriers to some extent. Since non-DBP transport results in more rapid hepatic uptake of vitamin D $(14,15)$, the plasma kinetics of administered vitamin $\mathrm{D}$ and the subsequent appearance of $25(\mathrm{OH}) \mathrm{D}$ in plasma are clearly affected by the modes of plasma transport and the prevailing stores of vitamin $D(2,6,22)$.

Comparisons of the bioavailability of vitamin D administered by various routes have been made. Whole body irradiation with effective UV light has resulted in plasma $25(\mathrm{OH}) \mathrm{D}$ levels comparable to those observed during oral consumption of $0.25 \mathrm{mg}$ of vitamin D daily (30). Single, intravenous doses of large amounts of vitamin $D$ result in relatively rapid increases of plasma $25(\mathrm{OH}) \mathrm{D}$ not unlike results seen after a single, large, oral dose (9). It appears probable that these brisk 
$25(\mathrm{OH}) \mathrm{D}$ responses are due to the initial association of administered vitamin D with non-DBP carriers. Oily depot (intramuscular or subcutaneous) injections of large doses of vitamin $D$ result in a more gradual egress from depot sites and more gradual increases and sustained plasma $25(\mathrm{OH}) \mathrm{D}$ levels $(9,31)$.

Since cutaneous production of vitamin $\mathrm{D}_{3}$ results in a gradual and more sustained plasma availability of vitamin $D$ and its bioactive product, 25 -hydroxyvitamin $\mathrm{D}$, this source is physiologically attuned to the recognized, intense economy of vitamin D stores $(2,6)$. Rapid hepatic delivery of vitamin D can result in its waste with the appearance of inactive forms, including water-soluble conjugates (2). Our present results clearly indicate that DBP plays a central role in the physiological economy of cutaneously derived vitamin $\mathrm{D}_{3}$.

\section{Acknowledgments}

We are grateful to Dr. J. Strauss of the University of Pennsylvania Reproductive Biology Division for helpful discussions and to Dr. M. Kamoun and Dr. L. Kricka of the University of Pennsylvania, Department of Pathology and Laboratory Medicine for helpful discussions, loan of equipment, and pilot analyses.

This work was supported in part by National Institutes of Health grant AM-28292.

\section{References}

1. Norman, A. W., and H. Henry. 1974. 1,25-Dihydroxycholecalciferol: a hormonally active form of vitamin $\mathrm{D}_{3}$. Recent Prog. Horm. Res. 30:431-479.

2. Fraser, D. R. 1983. The physiological economy of vitamin D. Lancet. i:969-972.

3. Haddad, J. G., and T. J. Hahn. 1973. Natural and synthetic sources of circulating 25-hydroxyvitamin D in man. Nature (Lond.). 244:515-517.

4. Stamp, T. C. B., and J. M. Round. 1974. Seasonal changes in human plasma levels of 25-hydroxyvitamin D. Nature (Lond.). 247:563-565.

5. Lawson, D. E. M., A. A. Paul, A. E. Black, T. J. Cole, A. R. Mandal, and M. Davie. 1979. Relative contributions of diet and sunlight to vitamin D state in the elderly. Br. Med. J. 2:303-305.

6. Haddad, J. G. 1987. Traffic, binding and cellular access of vitamin D sterols. In Bone and Mineral Research. 5th ed. W. A. Peck, editor. Elsevier Science Publishers B. V., Amsterdam. 281-308.

7. Poskitt, E. M. E., T. J. Cole, and D. E. M. Lawson. 1979. Diet, sunlight and 25-hydroxyvitamin D in healthy children and adults. Br. Med. J. 1:221-223.

8. Omdahl, J. L., P. J. Garry, L. A. Hunsaker, W. C. Hunt, and J. S. Goodwin. 1982. Nutritional status in a healthy elderly population: vitamin D. Am. J. Clin. Nutr. 36:1225-1233.

9. Whyte, M. P., J. G. Haddad, D. D. Walters, and T. C. B. Stamp. 1979. Vitamin D bioavailability: serum 25-hydroxyvitamin D levels in man after oral subcutaneous, intramuscular and intravenous vitamin $\mathrm{D}$ administration. $J$. Clin. Endocrinol. \& Metab. 48:906-911.

10. Holick, M. F., J. A. MacLaughlin, M. B. Clark, S. A. Holick, J. T. Potts, Jr., R. R. Anderson, I. H. Blank, J. A. Parrish, and P. Elias. 1980. Photosynthesis of previtamin $\mathrm{D}_{3}$ in human skin and the physiologic consequences. Science (Wash. DC). 210:203-205.

11. Holick, M. F., J. A. MacLaughlin, and S. H. Doppelt. 1981. Regulation of cutaneous previtamin $\mathrm{D}_{3}$ photosynthesis in man: skin pigment is not an essential regulator. Science (Wash. DC). 211:590-593.

12. Holick, M. F. 1987. Photosynthesis of vitamin D in the skin: effect of environmental and life-style variables. Fed. Proc. 46:1876-1882.

13. Barragry, J. M., M. W. France, B. J. Boucher, and R. D. Cohen. 1979. Metabolism of intravenously administered cholecalciferol in man. Clin. Endocrinol. 11:491-495.

14. Silver, J., and E. Berry. 1982. Vitamin D uptake by the perfused rat liver is determined by its transport protein. Miner. Electrolyte Metab. 7:298-304.

15. Haddad, J. G., A. S. Jennings, and T. C. Aw. 1988. Vitamin D uptake and metabolism by perfused rat liver: influences of carrier proteins. Endocrinology. 123:498-504.

16. Haddad, J. G., D. P. Aden, and T. C. Aw. 1989. Plasma carriers influence the uptake of cholecalciferol by human hepatoma-derived cells. J. Bone Miner. Res. 4:243-247.

17. Chung, B. H., T. Wilkinson, J. C. Geer, and J. P. Segrest. 1980. Preparative and quantitative isolation of plasma lipoproteins: rapid, single discontinuous density gradient ultracentrifugation in a vertical rotor. J. Lipid Res. 21:284-291.

18. Hollis, B. W., and N. E. Frank. 1985. Solid phase extraction of vitamin D and its major metabolites from human plasma. J. Chromatogr. 343:43-49.

19. Haddad, J. G., J. Abrams, and J. Walgate. 1981. Affinity chromatography with 25 hydroxycholecalciferol ester in the isolation of the binding protein for vitamin D and its metabolites from human serum. Metab. Bone Dis. \& Relat. Res. 3:43-46.

20. Haddad, J. G., M. A. Kowalski, and E. Lange. 1985. Selective, rapid removal of the vitamin D-binding protein and its sterol liquids from human and bovine plasma. Anal. Biochem. 146:96-102.

21. Lawson, D. E. M., S. H. Sedrani, and J. Douglas. 1986. Interrelation-ships in rats of tissue pools of cholecalciferol and 25-hydroxy-cholecalciferol formed in U.V. light. Biochem. J. 233:535-540.

22. Stanbury, S. W., E. B. Mawer, C. M. Taylor, and P. De Silva. 1980. The skin, vitamin $\mathrm{D}$ and the control of its 25 -hydroxylation: An attempted integration. Miner. Electrolyte Metab. 3:51-60.

23. Avioli, L. V. 1969. Absorption and metabolism of vitamin $\mathrm{D}_{3}$ in man. Am. J. Clin. Nutr. 22:437-446.

24. Dueland, S., P. Helgerud, J. I. Pedersen, T. Berg, and C. A. Drevon. 1983. Plasma clearance, transfer and distribution of vitamin $D_{3}$ from intestinal lymph. Am. J. Physiol. 245:E326-E331.

25. Dueland, S., J. I. Pederson, P. Helgerud, and C. A. Drevon. 1982. Transport of vitamin $\mathrm{D}_{3}$ from rat intestine. J. Biol. Chem. 257:146-150.

26. Dueland, S., J. I. Pederson, P. Helgerud, and C. A. Drevon. 1983. Absorption, distribution and transport of vitamin $D_{3}$ and 25-hydroxyvitamin $D$ in the rat. Am. J. Physiol. 245:E463-E467.

27. Okano, T., S. Masuda, M. Ishimine, J. Murai, Y. Yamamoto, and T. Kobayashi. 1983. Existence of vitamin $D_{3}$ and 25-hydroxyvitamin $D_{3}$ in rat lymph. Chem. Pharm. Bull. (Tokyo). 31:3233-3241.

28. Avioli, L. V., S. W. Lee, J. E. McDonald, J. Lund, and H. F. DeLuca 1967. Metabolism of vitamin $\mathrm{D}_{3}{ }^{-3} \mathrm{H}$ in human subjects: distribution in blood, bile, feces and urine. J. Clin. Invest. 46:983-992.

29. Rojanasathit, S., and J. G. Haddad. 1976. Hepatic accumulation of vita$\min \mathrm{D}_{3}$ and 25-hydroxyvitamin $\mathrm{D}_{3}$. Biochim. Biophys. Acta. 421:12-21.

30. Stamp, T. C. B., J. G. Haddad, and C. A. Twigg. 1977. Comparison of oral 25 hydroxycholecalciferol, vitamin D and ultraviolet light as determinants of circulating 25-hydroxyvitamin D. Lancet. i:1341-1343.

31. Davies, M., and E. B. Mawer. 1979. The absorption and metabolism of vitamin $\mathrm{D}_{3}$ from parenteral injection sites. In Vitamin $\mathrm{D}$, Basic Research and Its Clinical Application. A. W. Norman, K. Schaefer, H. G. Grigoleit, and D. von Herrath, editors. Walter de Gruyter \& Co., Berlin, New York. 609-612. 